\title{
CLOUD ATTENUATION AT Ka, Q AND W BANDS BASED ON RADIOSOUNDINGS DURING RAINY AND NON-RAINY SEASONS IN CENTRAL ANDES: A STUDY IN EL ALTO, BOLIVIA
}

\author{
Alejandro Garcia, Gustavo Siles, Juan Pablo Arciénega and Yasmin Balderrama
}

\begin{abstract}
Cloud attenuation in satellite communication systems becomes a relevant issue as the frequency increases, and thus, it has to be taken into account when link availability is being calculated. This atmospheric impairment is a variable atmospheric phenomenon whose characterization has to be done not only on a yearly-basis but also on a seasonal and monthly basis. In the present paper, cloud attenuation statistics are reported at $20 \mathrm{GHz}, 40 \mathrm{GHz}$ and $75 \mathrm{GHz}$ during rainy and non-rainy seasons in El Alto, Bolivia, at $4065 \mathrm{~m}$ of altitude, using 3 years of radiosoundings (2016-2019). Cloud detection models have been used for the calculations, including Salonen, Salonen08, Decker and CldMod models, and results obtained are compared to those given by the global model of the ITU-R Rec. P.840. The results lead to conclude that zenith cloud attenuation during rainy season can reach maximum values between 0.15 and $0.45 \mathrm{~dB}(20$ $\mathrm{GHz}), 0.55$ and $1.5 \mathrm{~dB}(40 \mathrm{GHz})$, and 1.3 and $3.9 \mathrm{~dB}(75 \mathrm{GHz})$ depending on the model to be used. In comparison, during non-rainy season these values vary between 0.08 and $0.33 \mathrm{~dB}(20 \mathrm{GHz}), 0.26$ and $1.1 \mathrm{~dB}(40 \mathrm{GHz})$, and $0.62 \mathrm{and}$ $2.6 \mathrm{~dB}(75 \mathrm{GHz})$. On the other hand, statistics based on CldMod model and, in a less extent, Decker model are close to the ones obtained using the ITU-R global model. These observations could open the possibility of further studies assessing the reliability of meteorological parameters in digital maps at high altitude sites, because these data are used in global propagation models.
\end{abstract}

Keywords: Satellite Communications, Cloud Attenuation, Propagation, Radiosoundings.

DOI: 10.23881/idupbo.021.1-1i 